\title{
CIDADE, POLÍTICA E URBANISMO: DEBATES E DESAFIOS NO RECONHECIMENTO DE UM CENTRO HISTÓRICO METROPOLITANO
}

\section{Cleusa Maria Gomes Graebin ${ }^{1}$ Danielle Heberle Viegas ${ }^{2}$}

A cidade de Canoas/RS, hoje um Município referencial no conjunto das regiões metropolitanas do Sul do Brasil, encontra a sua origem histórica na sesmaria doada ao tropeiro Francisco Pinto Bandeira em 1732. Mas foi a partir de sua emancipação do Município de Gravataí, em 1939, que a cidade desenvolveu a configuração urbana que a tornou conhecida, tendo sido promovida no discurso jornalístico da época como uma "sala de visitas de Porto Alegre". Uma vez assim denominada, seus primeiros governantes trabalharam no sentido de que fizesse jus ao seu novo statuse se apresentasse como um espaço organizado e aprazível.

Já no discurso de sua posse, o primeiro Prefeito nomeado em 1941, Edgar Braga da Fontoura, disse que a sua política consistiria em

[...] trabalhar, preocupando-se com a instrução pública $e$ as estradas para, depois, vir atender a parte referente à urbanização da sede da nova comuna. Outros dois problemas, acrescentou, ainda o preocupavam: os de serviços de eletricidade e dos transportes, entregue a empresas particulares ${ }^{4}$.

$\mathrm{Na}$ cidade em que "tudo estava por fazer" 5 , o primeiro passo era o de, naturalmente, refletir sobre como fazer tudo. Uma das demandas mais prementes era onde localizar o que as autoridades então constituídas $e$ os representantes da sociedade canoense entendiam na época por centro cívico. Passadas quase oito décadas da emancipação, o tecido urbano da cidade é morfologicamente marcado por uma estrada federal, uma linha ferroviária e por uma linha de metrô de superfície e os canoenses ainda se perguntam sobre a constituição e os usos possíveis da área central da cidade, acrescentando outras questões: A cidade tem um centro histórico? Em caso positivo, quais os elementos que o caracterizam como tal e qual o seu perímetro?

As autoras, além de residirem em Canoas e de se envolverem diretamente com as questões locais, têm se dedicado a pesquisar sobre sua trajetória histórica e foram convidadas a colaborar com a Secretaria Municipal de Cultura e Turismo em

\footnotetext{
${ }^{1}$ Doutora em História (UNISINOS, 2004). Professora do Programa de Pós-Graduação em Memória Social e Bens Culturais da Universidade La Salle. E-mail: <cleusa.graebin@unilasalle.edu.br>.

${ }^{2}$ Doutora em História (PUCRS, 2016). Professora do Programa de Pós-Graduação em Memória Social e Bens Culturais da Universidade La Salle. E-mail: <danielle.viegas@unilasalle.edu.br>.

${ }^{3}$ A Notícia, Canoas, 21.07.1940.

${ }^{4}$ Folha da Tarde, Porto Alegre, 15.01.1940.

${ }^{5}$ A Notícia, Canoas, 28.07/1940.
} 
investigação e constituição do centro histórico da cidade. É o resultado deste trabalho que ora se relata, apoiado no pensamento de Stella Bresciani ${ }^{6}$, indicando que a questão urbana se estrutura no e pelo debate político.

Teoricamente, fundamenta-se na ideia de que a cidade se constrói a partir de planejamentos, por aglomerados e conjuntos de edificações, por vias de acesso, etc., porém, antes de tudo isto, é espaço de relacionamentos, é construção e realidade sociocultural, política e econômica. Toda a sua dinâmica está inscrita nos seus becos, ruas e avenidas; seus habitantes, visitantes, os flaneurs constroem simbolismos, representações e significados sobre ela, dela se apropriam, vivendo, experenciando as suas múltiplas possibilidades. Monteiro ${ }^{7}$ trata sobre o desafio do fazer a História da Cidade, indicando diferenças em relação à História Urbana, sobre os objetos diferenciados sobre os quais se debruçam aqueles que encaram o seu fazer. Neste sentido, nas pesquisas, tem-se dado atenção à vida que pulsa nas cidades, às sensibilidades, à construção de memórias, às discussões sobre patrimônio cultural, à construção de territórios, às disputas políticas, às políticas públicas, às linguagens, às representações, às imagens, entre outros. Centrais para este estudo são os conceitos de centro cívico e centro histórico que se passa a discutir na sequência do texto.

Trabalhou-se com a metodologia da História Oral e com acervo de entrevistas temáticas ${ }^{8}$ resultantes do Projeto "Canoas - Para lembrar quem somos", entendendo-o como ponto de partida para outras pesquisas sobre a cidade. Também, constituiu-se um corpus com documentos oficiais, legislação sobre patrimônio cultural, mapas, planos urbanísticos, escritos de memorialistas locais e imagens fotográficas que permitissem compreender a cidade, captando sua trajetória no tempo.

\section{Onde será o centro cívico? Entre disputas políticas e teorias urbanas}

Realizada a emancipação em 1939 e instalado o primeiro prefeito e a Câmara de Vereadores em 1940, a princípio, não foi criado nenhum órgão voltado exclusivamente para o tratamento das demandas urbanísticas. A Prefeitura de Canoas instalou-se com poucos recursos e contava em seu quadro de funcionários apenas com um secretário, um contador, um tesoureiro, dois escriturários, um fiscal lotador,

${ }^{6}$ BRESCIANI, Maria Stella. Cidade e História. In: OLIVEIRA, Lucia Lippi de (org.). Cidade: História e desafios. Rio de Janeiro: Editora da FGV, 2002, p. 19.

${ }^{7}$ MONTEIRO, Charles. Entre História Urbana e História da Cidade: questões e debates. Oficina do Historiador, Porto Alegre, EDIPUCRS, v. 5, n.1, jan./jun. 2012, pp. 101-112. Disponível em http://revistaseletronicas.pucrs.br/ojs/index.php/oficinadohistoriador/article/view/11835/8320. Acesso em 12/06/2016.

${ }^{8}$ Este tipo de entrevista tem como características dirigir o foco para a participação dos entrevistados nos eventos do interesse da investigação em curso. Sobre entrevista temática, ver: ALBERTI, Verena. Manual de História Oral. Rio de Janeiro: FGV, 2004.

${ }_{9}^{9}$ As entrevistas fazem parte do acervo do Projeto Canoas - Para lembrar quem somos. Trata-se de pesquisa em parceria com a Prefeitura Municipal de Canoas, em desenvolvimento desde 1994, que trabalha com a construção de memórias sobre a cidade e seus bairros. O acervo está sob a guarda do Museu Histórico La Salle (Universidade La Salle). 
um porteiro-contínuo, um subprefeito para o primeiro distrito (na sede) e outro para o segundo distrito - Santa Rita ${ }^{10}$.

Uma vez estando o Poder Público organizado, mesmo que sem uma pauta expressa voltada aos temas urbanos, a realização de algumas obras tornou-se motivo de realce. De imediato, menciona-se a inauguração de um espaço em que "a população costuma passar horas de descanso ao ar livre" conforme o jornal A Notícia (21/07/1940). Consistia em ampla área localizada em frente à Igreja Matriz da cidade, entregue remodelada e ajardinada aos canoenses, sob o nome de Praça da Bandeira $^{11}$.

Aqui já se coloca um problema a ser discutido, em termos de estudos históricos urbanos, tendo em vista o conceito de "centro cívico" e de "centro histórico". Roberto da Matta ${ }^{12}$ chama a atenção para como, em diferentes sociedades, se manifesta o espaço, colocando que nas cidades do Brasil a constituição de um centro traz em si a ideia de "cidade", de uma hierarquia entre aquele e a periferia; que há uma demarcação não só espacial, mas também social que remete ao cidadão estar dentro ou fora, vivendo, simultaneamente, muitos espaços e temporalidades. Isso leva à compreensão de que o centro da cidade, como espaço, é constituído e delimitado socialmente, num fenômeno que envolve a sua gênese, decisões sobre suas fronteiras, como se legitima e sobre sua aceitação pela comunidade. Centro histórico é definido "[...] como sendo um espaço físico condicionado pelas relações que se foram estabelecendo entre as pessoas, ao longo do tempo"13. Então, falar de centro cívico e de centro histórico envolve tratar de espaço, de tempo e de narrativas construídas que organizam experiências, que constituem processos, que orientam procedimentos coletivos.

O local que se transformou em Praça da Bandeira já se constituía como espaço comercial - ali, estava localizada, desde 1912, a Casa Vargas, grande armazém de secos, molhados, ferragens, fazendas e louças. Nas imediações, havia uma Estação da ferrovia que ligava a capital, Porto Alegre, a São Leopoldo (polo de irradiação da colonização alemã no Rio Grande do Sul). Próximo estava o Instituto São José, escola fundada pelos Irmãos Lassalistas em 1908, os quais levavam os alunos para partidas de futebol no campo lá existente; também era ponto de descanso e lazer dos moradores das adjacências. Desde 1933, uma Comissão constituída para pleitear melhoramentos para o então Distrito de Gravataí, já havia solicitado obras para a construção de uma praça, levadas a efeito pelo subprefeito.

\footnotetext{
${ }^{10}$ De acordo com CANOAS. Decreto-Lei n. 8036, de 1939. Prefeitura Municipal de Canoas.

${ }^{11}$ O local já era conhecido como Praça Guilherme Schell, segundo SILVEIRA, Leila da. Igreja matriz São Luiz Gonzaga: a construção da Igreja e o desenvolvimento urbano de Canoas. Canoas: Prefeitura Municipa/Tecnicópias, 2007, p. 42.

${ }^{12}$ DA MATTA, Roberto. A casa \& a rua: espaço, cidadania, mulher e morte no Brasil. 5. Ed. Rio de Janeiro: Zahar, 1997. DA MATTA, Roberto. Carnavais, malandros e heróis: por uma sociologia do dilema brasileiro. Rio de janeiro: Zahar, 1983.

13 QUEIRÓS, Filipa. Reabilitação de Centros Históricos. Coimbra: Faculdade de Economia da Universidade de Coimbra, 2007, p. 9. Disponível em http://www4.fe.uc.pt/fontes/trabalhos/2007007.pdf. Acesso em 14/05/2016.
} 


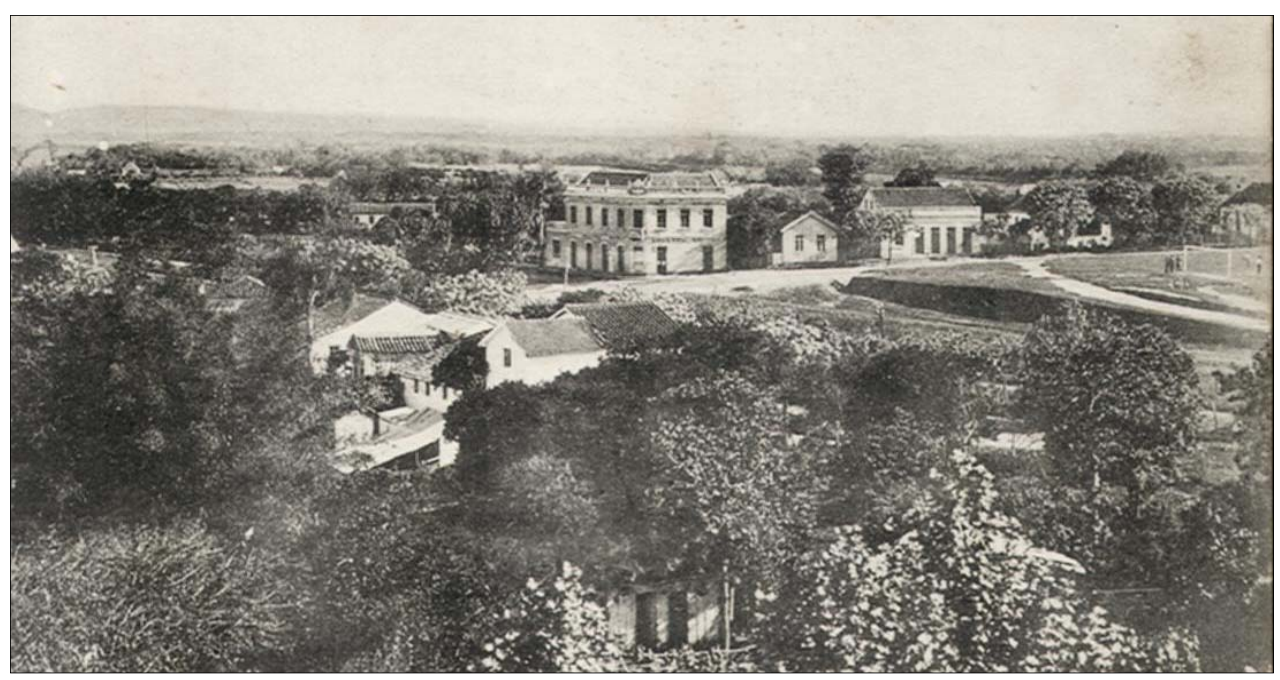

Figura 1: Vista do local onde foi construída a Praça da Bandeira.

No alto, no centro da imagem, a Casa Vargas (Canoas, década de 1930).

Fonte: Fototeca do Museu Histórico La Salle.

Ao analisar as narrativas dos entrevistados, a saber, Ernani Freitas, Arnildo Malmann, Hugo Simões Lagranha e Antonio Canabarro Trois, suas memórias permitem aproximar o que indicam como o "centro cívico" de Canoas, à imagem da Figura 1. Trata-se de um documento que preserva, congelados, fragmentos da cidade, os quais eram visíveis no passado. Nas investigações realizadas, a fotografia se constituiu como ponto de partida que se conectou a diversos pontos narrados, dando pistas para compreensão da aparência que teria o espaço do centro cívico, ou seja, da praça onde "a cidade acontecia". Segundo Da Matta ${ }^{14}$, as praças servem como lugares de encontro, de mediação de temporalidades. São espaços por excelência para as celebrações e comemorações e para divulgação de mensagens. Na Praça da Bandeira se cristalizou o poder espiritual, a partir da presença da Igreja Matriz de São Luiz Gonzaga, o poder do Estado, com a localização, na Casa Vargas, da sede da Prefeitura. O espaço teve relevância, também, por um monumento - a Pira da Pátria , sinalizando para um sistema de valores a operar e a emoldurar a vida social.

Embora nas lembranças dos entrevistados, já se esboce esse local como centro cívico, ainda no primeiro ano de instalação do Município, outro foi cogitado, o que corrobora a afirmação de $\mathrm{Da} \mathrm{Matta}^{15}$ que os espaços podem ser transitórios, problemáticos e que nem sempre são marcados pela eternidade, estando sujeitos à existência de conflitos. No caso de Canoas, o ano de 1941 se destaca pela ocorrência de uma grande enchente, evidenciando um constante problema para a sua urbanização, uma vez que a maior parte das terras faz parte das várzeas dos rios Gravataí e dos Sinos.

Assim, foram pensadas outras possibilidades para estabelecer a parte central da cidade, que coloca um bairro - o Marechal Rondon - em evidência, tanto pela escolha de residência nos altos da rua Santos Ferreira para sediar o Paço Municipal, quanto

${ }^{14}$ DA MATTA, Roberto. A casa \& a rua...

${ }^{15}$ DA MATTA, Roberto. A casa \& a rua... 
pela proposta do arquiteto e urbanista Ruy de Viveiros Leiria que, ao projetar um bairro modelar padrão para Canoas, não perdeu a oportunidade de elaborar um projeto para o centro cívico da nova municipalidade.

O "Pré-Plano para a cidade de Canoas" foi elaborado em 1944, mas publicado somente no ano de 1948, na Revista de Engenharia do Rio Grande do Sul, especializada em divulgar trabalhos urbanísticos na época. O texto consiste na integração de dois projetos, o da "Vila Mauá" (1941) e o da "Reurbanização da cidade de Canoas" (1944). Segundo o urbanista responsável, Rui de Leiria, um dos principais problemas de Canoas era a falta de um espaço no qual a população pudesse se reunir e manifestar-se publicamente, o que remete à ideia de praça com características de centro cívico ou, como refere Lamas, "um lugar intencional do encontro, da permanência, dos acontecimentos, de práticas sociais, de manifestações de vida urbana e comunitária e de prestígio, e, consequentemente, de funções estruturantes $e$ arquiteturas significativas". ${ }^{16}$

Canoas, em outras palavras, foi acusada pelo urbanista de não possuir a tendência natural para a formação de um centro cívico. Tal situação, segundo ele, podia ser facilmente explicada, devido à cidade ser "até o ano de 1940, um mero distrito do Município de Gravataí, onde se achava sediado o órgão central [...]"17. Tal afirmação é, contudo, discutível. Já indicamos que o território da chamada Praça da Bandeira, inaugurada no aniversário de Emancipação do Município, há muito sediava as principais manifestações públicas da população canoense, tal como o Comício da Comissão Pró-Melhoramentos, ainda em 1933. Em 1944, quando Ruy de Viveiros Leiria concluiu que inexistia um centro cívico em Canoas, a Prefeitura encontrava-se situada na citada Praça, no segundo andar da Casa Vargas. A negação da existência desse espaço, portanto, parece estar mais ligada àquelas inferências de que o local era urbanisticamente inadequado do que propriamente à sua não existência. Segundo o próprio Leiria, dizia a oitava página do seu Pré-Plano Diretor:

Acha-se atualmente (fins de 1944) sediada a Municipalidade à Praça da Bandeira em um prédio de construção mista, em péssimas condições higiênicas e localizado a 400 metros da Perimetral, a oeste da cidade. Não tem ligação direta com as outras repartições públicas, cujo contato com a Prefeitura deve ser necessariamente íntimo, estando, além disto, situado a oeste da Rodovia Federal e da Linha Férrea Canoas - São Leopoldo, zona que só poderia ser atingida depois de ser atravessar duas linhas de tráfego rodoviário e uma linha de tráfego ferroviário. ${ }^{18}$

Na época, segundo testemunho de Ernani de Freitas (chegado a Canoas em 1945), "a Prefeitura parecia mais um armazém do que outra coisa, a ponto de um

\footnotetext{
${ }^{16}$ LAMAS, José M. Ressano Garcia. Morfologia urbana e desenho da cidade. Lisboa: Fundação Calouste Gulbenkian, Junta Nacional de Investigação Científica e Tecnológica, 1990, p. 102.

${ }^{17}$ LEIRIA, Ruy de Viveiros. Pré-Plano para a cidade de Canoas. Revista de Engenharia do Rio Grande do Sul, Porto Alegre, n. 14, ano IV, p. 53-73, set. 1948. Acervo Biblioteca IPH, UFRGS.

${ }^{18}$ LEIRIA, Ruy de Viveiros. Pré-Plano para a cidade de Canoas...
} 
rapazinho um dia ir lá com uma garrafa, comprar cachaça, porque tinha um balcão de madeira [...] e, quando chovia, era muito barro por tudo quanto é lado"19.

As narrativas construídas pelos entrevistados, em relação à localização do centro cívico de Canoas, mostram que já havia se estabelecido uma disputa entre o poder público, algumas entidades e personagens de destaque na sociedade canoense, antes mesmo da existência do Projeto de Reurbanização, de 1944, ou ao Pré-Plano Diretor, de 1948. Isso porque a historiografia e memórias de representantes locais acusam que, ainda em 1941, o primeiro Prefeito de Canoas pediu exoneração do cargo em função de pressões por pensar em outro espaço para o centro cívico.

Hugo Simões Lagranha, ex-prefeito da cidade ${ }^{20}$, em entrevista, informou que o proprietário da Casa Vargas, Artur Pereira de Vargas, Vicente Claudio Porcello, dono da única farmácia de Canoas e outros não concordavam que o centro se localizasse fora dos limites da Estação da via férrea, Praça da Bandeira e estrada de rodagem que ligava Porto Alegre a São Leopoldo, cortando a cidade em duas partes. Infere-se que as discussões a respeito tenham tomado certas proporções, pois a imprensa local (jornal $A$ Notícia) buscava contemporizar:

Temos, portanto, o dever de confiar na ação do prefeito, em prol do engrandecimento desta gleba. Sua longa experiência, seu sistema de agir metodicamente, sem alarde, farão com que Canoas, num futuro não remoto, esteja colocada à altura das grandes cidades do Rio Grande. ${ }^{21}$

Ao refletir sobre as memórias de Hugo Simões Lagranha e Ernani Freitas, estas oferecem uma interpretação em torno das relações de poder que eram tecidas sobre o processo de urbanização de Canoas, alinhando-se às narrativas dos memorialistas locais. Neste sentido, reflete-se, com o apoio de Portelli ${ }^{22}$, sobre como as lembranças são iluminadas pelo contexto em que vive o narrador, o filtro que este utiliza, norteado pela sua inserção social $e$, neste caso, os enquadramentos ${ }^{23}$ de uma "memória oficial" já construída sobre a cidade.

A polêmica sobre o centro se estendeu para o Governo de Aluízio Palmeiro de Escobar (gestão 1941 a 1945). Tema peculiar à sua administração foi o fato de o então Prefeito ter sido acusado de perder o seu cargo em 1945 por conta do incentivo a obras que nunca pôde ver concluídas. Novamente, destaca-se que é divulgado pela historiografia que Escobar, bem como Braga da Fontoura, entraram em atrito com lideranças locais em função da localização do centro cívico.

\footnotetext{
${ }^{19}$ FREITAS, Ernani. Entrevista a Miguel Gayeski. Projeto Canoas - Para lembrar quem somos, 1996.

${ }^{20}$ LAGRANHA, Hugo Simões. Entrevista a Miguel Gaiesky. Projeto Canoas - Para lembrar quem somos, 1996.

${ }^{21}$ A Notícia, Canoas, 29/07/1940.

${ }^{22}$ PORTELLI, Alessandro. História Oral como arte da escuta. São Paulo: Letra e Voz, 2016.

${ }^{23}$ Cf. POLLAK, Michael. Memória e identidade social. Revista Estudos Históricos, Rio de Janeiro, v. 5, n. 10, p. 200-215, jul. 1992. ISSN 2178-1494. Disponível em: http://bibliotecadigital.fgu.br/ ojs/index.php/reh/article/view/1941. Acesso em: 15 Abr. 2016. (grifo nosso)
} 
Exemplo disso vem com João Palma da Silva, em suas duas obras dedicadas à Canoas. Em um de seus textos, publicado originalmente em 1964, o autor declara que

[...] o Prefeito Escobar passou a elaborar um Código de Construções, com vistas não apenas ao problema das cheias, mas ao futuro crescimento da cidade. E como seu antecessor, planejou mudar o Centro Cívico da cidade para o alto da Rua Santos Ferreira. No mencionado Código, não foram esquecidas as funções vitais indispensáveis a qualquer cidade, tais como circulação, habitação, recreação e trabalho. ${ }^{24}$

Em 1978, o memorialista reafirma a sua concepção sobre o episódio:

Aluízio Palmeiro de Escobar tentou inutilmente mudar o Centro Cívico e urbano da cidade para a zona alta e afastada das estradas (rodagem e ferrovia) de Porto Alegre a São Leopoldo. Foi vencido pelo jogo de interesses, como fora o seu antecessor. Entretanto, Escobar pôde construir escolas, estradas e realizar outros melhoramentos. ${ }^{25}$

Ao se observar os detalhes grifados nas citações, no entanto, desvela-se novamente certa incongruência entre as narrativas e o projeto do urbanista Leiria, uma vez que nas pertinentes explanações sobre o desenvolvimento da cidade junto ao alto da rua Santos Ferreira, os estudiosos inclúram, sem pestanejar, o suposto desejo de instalação do centro cívico da cidade na área, o que contraria, absolutamente, as fontes cartográficas consultadas.

As Plantas apontam para outros caminhos - literalmente. Embora a transferência (ou a criação) do centro cívico tenha sido planejada, o espaço eleito para abrigar o novo empreendimento não foi "os altos da Rua Santos Ferreira", mas um quarteirão localizado há poucos metros da Estrada de Rodagem Federal, como se visualiza nas imagens compartilhadas a seguir. Os documentos correspondem, respectivamente, à Planta do Projeto de Reurbanização da cidade (Fig. 2) e à projeção detalhada de seu Centro Cívico (Fig. 3).

\footnotetext{
${ }^{24}$ SILVA, João Palma da. As origens de Canoas: conquista, povoamento, evolução. 4. ed. Canoas: La Salle, 1989. p. 149. p. 176.

${ }^{25}$ SILVA, João Palma da. Pequena História de Canoas - cronologia. Canoas: La Salle, 1978, p. 170. (grifo nosso)
} 


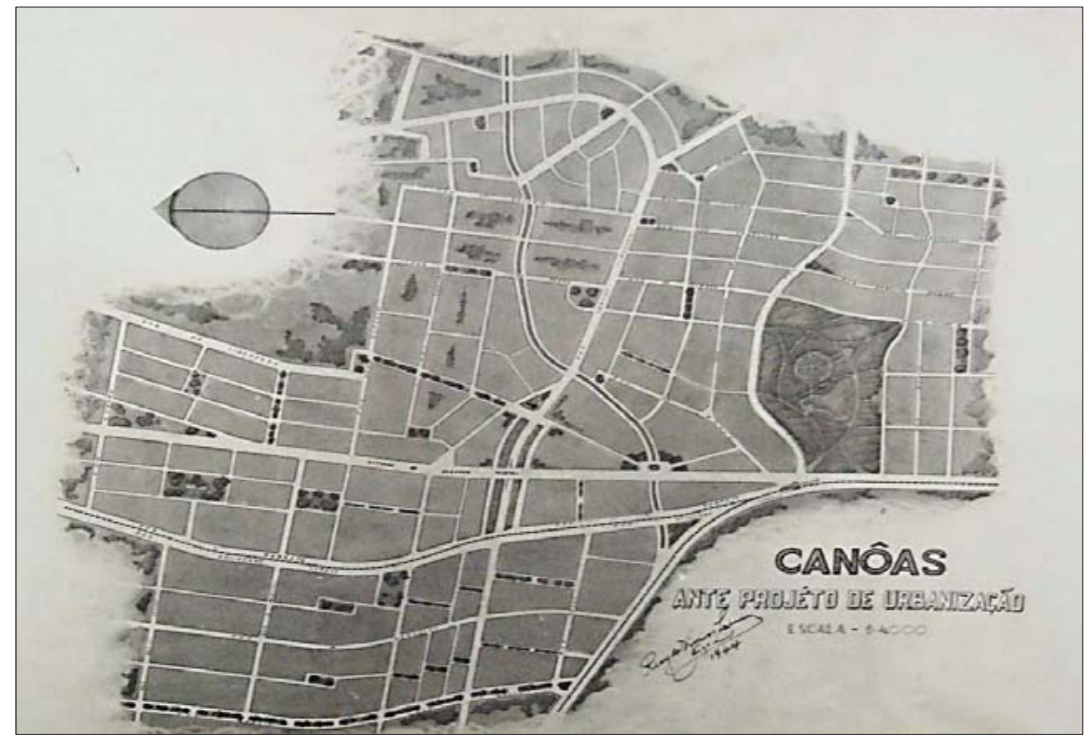

Figura 2: Planta geral do Projeto de Reurbanização de Canoas, 1944.

Fonte: Extraído da Revista de Engenharia do Rio Grande do Sul, 1948. Acervo IPH UFRGS.

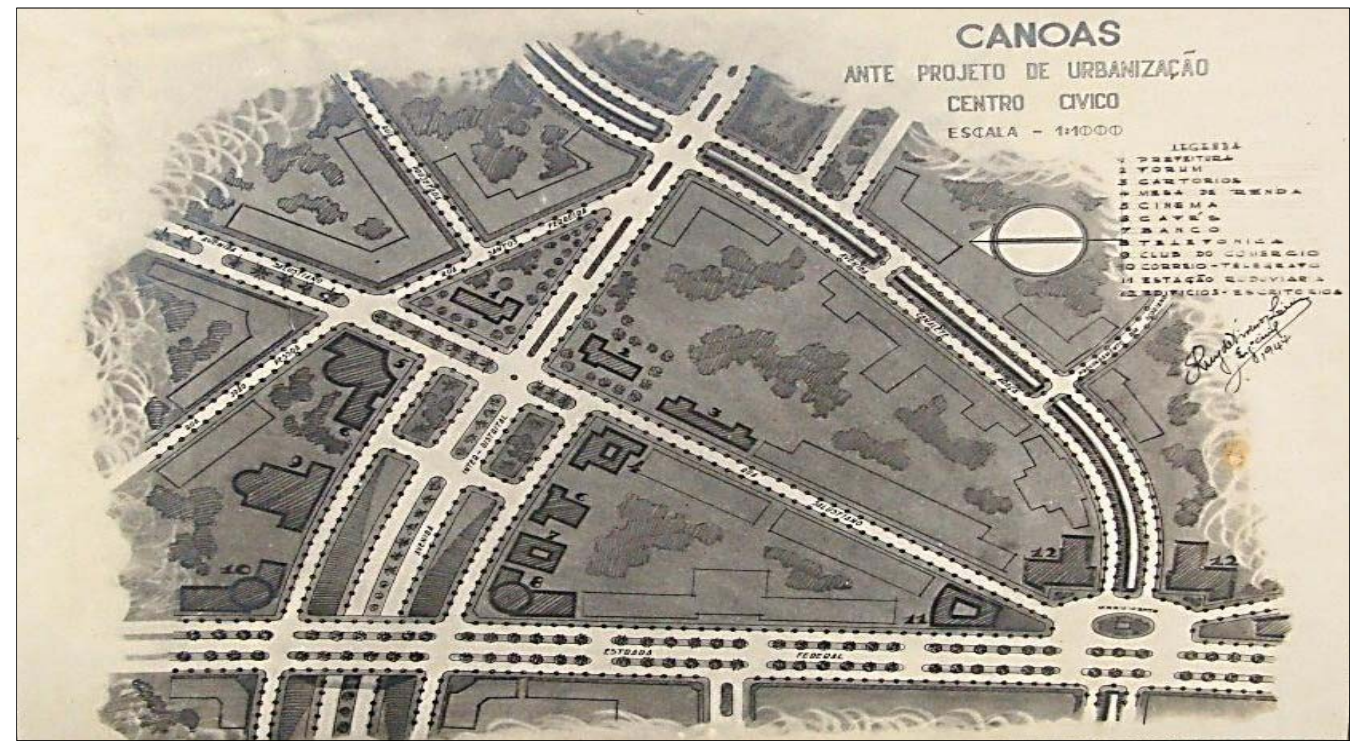

Figura 3: Detalhe do Planejamento do Centro Cívico de Canoa junto ao Bairro Marechal Rondon. Fonte: Extraído da Revista de1944.

Engenharia do Rio Grande do Sul, 1948. Acervo IPH UFRGS.

Os detalhes revelados (Figura 3) incluem a localização do centro cívico, planejado "em torno de um parque criado pelo alargamento da Avenida Interdistrital, entre a Rua Gal. Salustiano e a Rodovia Getúlio Vargas"26, ou seja, no coração histórico do Bairro Marechal Rondon. A rua General Salustiano, uma das mais antigas de toda a

${ }^{26}$ LEIRIA, Ruy de Viveiros. Pré-Plano para a cidade de Canoas. Revista de Engenharia do Rio Grande do Sul, Porto Alegre, n. 14, ano IV, p. 53-73, set. 1948. Acervo Biblioteca IPH, UFRGS, p. 53-57. 
Canoas, estava reservada para a edificação da Prefeitura Municipal, bem como do Fórum e do Cartório da cidade, além de um cinema e escritórios, que seriam construídos no final da rua, quando esta última encontrava a Rodovia Federal.

O urbanista apresenta um levantamento dos argumentos que o levaram a eleger o atual Marechal Rondon como a área mais propícia para instalar o centro cívico da comunidade, dividida a partir dos seguintes critérios: a) de ordem cívico-patriótica, b) de ordem viária, c) de ordem administrativa, d) de ordem econômica, e) de ordem estética.

Entre os motivos de maior relevância, está o fato de a área ser ampla e, portanto, adequada para grandes concentrações a fim de "comemorar datas nacionais, escolares, políticas e cívicas", podendo o largo "estar completamente cheio pela massa popular" 27 . O local também usufruía de ótimas condições técnicas, estando situado junto à Rodovia Federal, de onde se poderia ter plena visibilidade do grande centro e garantir o acesso a Porto Alegre e a outras localidades do Estado o que, de fato, caracteriza o bairro até a atualidade.

Também, a entrada em outras regiões da cidade seria facilitada por intermédio da Avenida Interdistrital, a qual se dá ênfase aqui pelo seu projeto arrojado, que previa um trecho a ser construído em nível inferior à rodovia, que daria acesso ao "outro lado" da rodovia, qual seja, à atual Praça Santos Dumont, popularmente conhecida como Praça do Avião. Além disso, corroborando os outros planos inclusos no Plano Diretor, o centro cívico foi pensado no que diz respeito à sua ligação com os outros empreendimentos a serem realizados, como a zona de comércio, prevista para a área a oeste da cidade, do lado oposto do centro cívico. Também a zona industrial é mencionada, igualmente, "ligada aos centros cívico e comercial". Resta perguntar quais foram os motivos que levaram os estudiosos de Canoas, como João Palma da Silva e Jesus Pfeil, a estarem convictos de que a instalação do Centro Cívico estaria localizada na zona alta da cidade, na rua Santos Ferreira. A memória citadina respalda o debate sobre a influência das lideranças locais em manter a "centralidade" da cidade nas suas terras, junto à antiga estação de trem (na Praça da Bandeira), ainda que o centro cívico de Marechal Rondon não fosse tão distante dali.

Arnildo Mallmann, secretário do prefeito Aluízio de Escobar à época, também cita nomes, alguns dos quais fazem correspondência com os citados por Lagranha, já referido.

Era Doutor Victor, o Artur Pereira de Vargas, o Ulisses Gomes Ferreira, o Dr. Sezefredo, o Afonso Charlier, o Ulisses Machado. E o Doutor Aluízio não tinha aquele jogo de cintura para ajeitar-se às situações, mas ele teve uma antevisão, ele quis construir uma nova cidade, mas seu objetivo foi obstaculizado por interesses que hoje vejo mais sensatos: querem um túnel para unificar a cidade ${ }^{28}$.

\footnotetext{
${ }^{27}$ LEIRIA, Ruy de Viveiros. Pré-Plano para a cidade de Canoas....

${ }^{28}$ MALMANN, Arnildo. Entrevista ao Projeto História de nossos Prefeitos, reproduzida em História de nossos Prefeitos. Aluízio Palmeiro de Escobar. v. 2. Canoas: Fundação Cultural de Canoas, 1999, p. 133. Série Documento. (grifo nosso).
} 
O primeiro e o segundo prefeito não foram ouvidos! Não foram escutados com respeito. O Edgar Braga da Fontoura e o Aloysio Escobar viram! [...] até onde ia a água do rio! O rio vinha até a rua Brasil![...] O Aloysio especialmente que decretou utilidade pública de uma área enorme que vai da Santos Ferreira até a Boqueirão [...] e ali criou uma vila popular! Contratou um urbanista de Porto Alegre, projetou tudo, acabou perdendo na justiça, foi demitido. Na época só havia um casarão, Frangosul, o resto tudo era em palafitas! Nenhuma residência seria construída em banhado! ... Os dois não foram ouvidos! O Edgar pediu demissão desgostoso com a resistência! O Aloysio foi morar na Chácara Barreto lá em cima, já tentando o centro mais para cima! Para Canoas não sofrer! Os dois foram embora! E aí o terceiro prefeito liberou as vendas dos terrenos! [...] baratinho, porque o loteador não tinha que fazer obras de infraestrutura, saneamento básico, vendia bem baratinho e ia embora! E ficava o problema para a Prefeitura. Por via natural ficou o problema para a população que pagou imposto! Então, tinha que socar pedras nas ruas para elevar o nível da rua, a escolinha, o ônibus que ia até lá, o serviço de saúde! Custou fortunas isso! [...] Quanto custou para Canoas? ${ }^{29}$

A partir dos depoimentos, percebe-se que a rede de interesses torna-se ainda mais complexa, quando esferas até então não cogitadas entram em cena:

[...] o Dr. Aluízio e sua esposa não eram muito de frequentar a igreja, então o Padre Leão, como intérprete de todos os paroquianos, ficou com aquele grupo [contrário às mudanças na cidade]. Mas ele divergia com lealdade; outros solertemente.. ${ }^{30}$

Tal como a Vila Popular Mauá, também projetada por Leiria, no período em que os documentos foram publicamente divulgados, em 1948, os traços desenhados pelo urbanista já se apagavam em prol de mudanças significativamente contrárias aos seus propósitos. Isso porque, enquanto se arquivam processos, traziam-se outros à tona.

No caso do centro cívico, elegeu-se alternativa para sua instalação, que não foi no bairro Marechal Rondon, nem junto à Praça da Bandeira, onde na década de 1940 localizava-se a Prefeitura. Quando da construção de uma sede própria para essa, o

29 TROIS, Antônio Canabarro. Entrevista em 18/01/2010 a Cleusa Maria Gomes Graebin. Projeto História da Câmara de Industria, Comércio e Serviços - CICS. Canoas, 2010.

${ }^{30}$ MALMANN, Arnildo. Entrevista ao Projeto História de nossos Prefeitos, reproduzida em HISTÓRIA de nossos Prefeitos. Aluízio Palmeiro de Escobar. v. 2. Canoas: Fundação Cultural de Canoas, 1999, p. 133. (Série Documento). 
local escolhido foi entre a via férrea e a estrada de rodagem. Até ser construído neste espaço, o Paço Municipal passou pela rua Santos Ferreira, na propriedade da família Ludwig, no segundo andar da chamada Casa Vargas, junto à Praça da Bandeira; na propriedade de Antônio Cândido da Silveira, na rua João Pessoa (atual rua Tiradentes); e, por fim, na rua 15 de Janeiro.

Uma vez estando abandonados os planos de Ruy de Viveiros Leiria, consta que foi adquirido, durante o mandato de Nelson Paim Terra, em 1946, um terreno para abrigar a sede da Prefeitura Municipal. Após tantos trâmites, o Prédio só veio a ser utilizado a partir de 1954, durante o Governo de Sady Schivitz. O centro cívico constituiu-se, enfim, com a organização, logo à frente do Prédio da Prefeitura, da chamada Praça da Emancipação, inaugurada na administração de Sezefredo Azambuja Vieira.

Por algum tempo, o referido logradouro passou a substituir a Praça da Bandeira, defronte à Igreja Matriz de Canoas, como o local de celebrações oficiais da municipalidade.

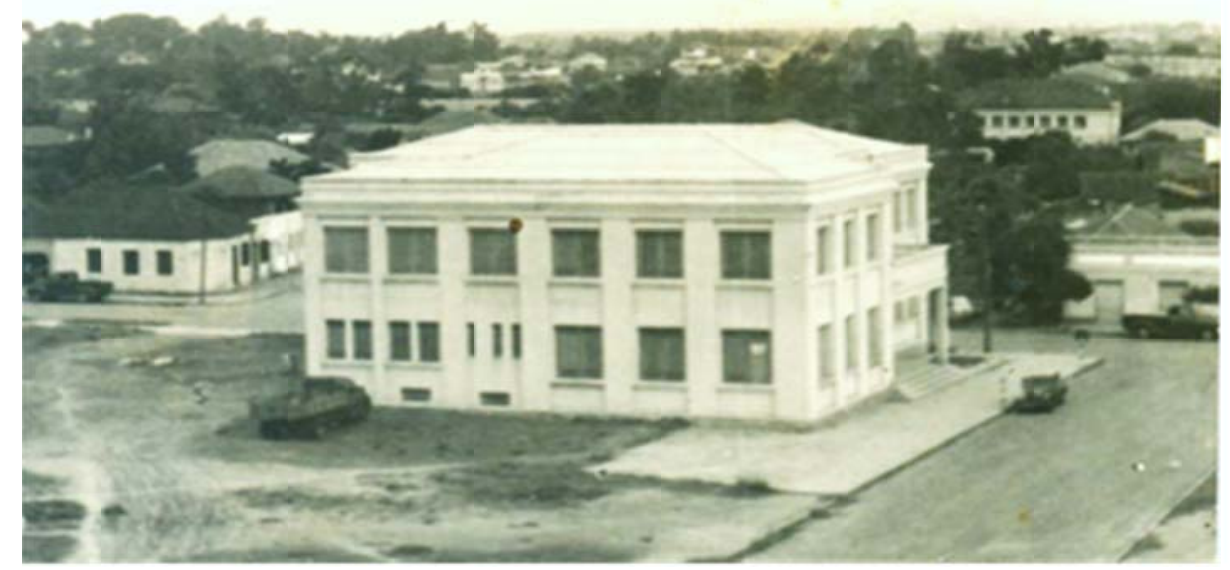

Figura 4: Prédio da Prefeitura de Canoas (1953)

Fonte: Arquivo Público Dr. Sezefredo Azambuja Vieira (Canoas)

A Praça Emancipação foi inaugurada em 26 de abril de 1958, sendo popularmente chamada de Praça da Prefeitura. A propósito, antes mesmo de ser construído, o espaço da praça era tido como largo da prefeitura e ali corriam eventos importantes na cidade, como o protesto pelo aumento do custo de vida (1955), organizado pela Liga de Emancipação Nacional, Núcleo de Canoas. Originalmente, possuía um chafariz e um aquário e seu projeto foi elaborado pela Diretoria de Educação e Cultura, através do Serviço de Recreação Pública - Setor de Praças e Jardins. Segundo o projeto,

[...] seu traçado obedeceu a mais moderna técnica de elaboração, que consiste em deixar a área nivelada entregue 
ao trânsito público, marcando pelos vestígios os futuros caminhos. Tal técnica fez com que os caminhos marcados e os canteiros traçados não sejam mais pisoteados. ${ }^{31}$

A praça possuía "calçada com mosaicos brancos e pretos; caramanchão (pérgola) com sombra para descanso e estar; tanque d'água com chafariz luminoso e placa comemorativa da inauguração ${ }^{32}$. Posteriormente, com reformas ocorridas, foram retirados o chafariz e o tanque.

A praça passou a abrigar monumentos importantes para a "memória oficial" da cidade. Em 1968 foi inaugurado o Monumento do Sino, em homenagem à princesa Isabel, que teria visitado a região em 1885. Segundo a tradição oral, o sino originalmente pertencia à fazenda da família Borges de Lima, situada na região de Morretes (atualmente município de Nova Santa Rita) e seu toque chamava empregados e escravos para as refeições. Relatos indicam que a princesa teria feito toque do sino para chamar os escravos da fazenda. No entanto, nada está registrado no Diário da Princesa, no qual anotava todos os acontecimentos ocorridos em suas viagens. O sino passou a pertencer a Ricardo de Freitas e depois a Lauro Pires de Moraes, antigo capataz da fazenda Borges de Lima. Esse doou o sino a Hugo Simões Lagranha em 1960.

Outro monumento é a obra denominada Futuro, escultura de Vinício Cassiano em homenagem ao trabalhador. Representa a trilogia humana do trabalho que leva ao progresso: em uma canoa há três personagens: o primeiro representa o trabalhador braçal, o segundo, o intelectual, e o terceiro, o empresário com o braço estendido apontando para o horizonte. Pelas características da obra, pode-se inferir que o autor teria como fundamentação o positivismo de Comte (século XIX). O título da obra foi escolhido pela comunidade e alunos das escolas municipais do Rio Grande do Sul, Rio de Janeiro, Edgar Fontoura, Ícaro, Arthur Pereira de Vargas, Duque de Caxias e Farroupilha (Diário de Canoas, 26/06/1998). A praça é o lugar de feiras de artesanato e de economia solidária, bem como tem sido o núcleo das atividades natalinas dos canoenses.

A imagem da Figura 4 pode provocar no observador uma síntese da memória construída sobre a cidade, fixando o novo local (o real referenciado) como espaço por excelência para o centro cívico. A fotografia pode ser manuseada, porém, aquilo que representava e que está ali fixado não o é mais importante no presente: as atividades cívicas e as comemorações da Semana da Pátria, Semana de Canoas, Feira do Livro, voltaram para a Praça da Bandeira. A foto, hoje, é um referente do que foi captado nos anos 1950, atualizando as lembranças de quem a vê, trazendo fragmentos do passado que nela não estão visíveis. Quando a imagem foi mostrada para dois dos entrevistados, as suas lembranças foram por ela informadas. A fotografia, então, articula o que refere àqueles que a interpretam $e$ que constroem uma narrativa a partir da imagem. Pode-se inferir que a fotografia atua como um sociotransmissor,

\footnotetext{
${ }^{31}$ Diário de Canoas, Praça da Emancipação, 26/02/1993.

${ }^{32}$ PFEIL, Jesus. Canoas: anatomia de uma cidade. Vol. II. Canoas: Ponto Um Gráfica e Editora, 1995, p. 418.
} 
isto é, um elemento atuante na rememoração, levando o observador a compartilhar lembranças, dando materialidade às experiências. ${ }^{33}$

A Lei $\mathrm{n}^{\circ}$ 456, de 31 de dezembro de 1956, no seu Artigod 4, constituiu o perímetro central da cidade, formado da seguinte maneira:

Rua Domingos Martins, entre a Rodovia BR-2 e a Avenida Victor Barreto; Rua José Muck Filho; a Avenida João Pessoa; a Rua Luiz Milanez; a Rua Frei Orlando; a Rua Sady Carnot; a Praça da Bandeira; a Rua Araçá, entre os trilhos da Viação Férrea e a Rua Brasil; a Rua Coronel Vicente, entre a Praça da Bandeira e a Rua Dr. Barcelos; a Rua Guilherme Schell, entre a Praça da Bandeira e a Rua Franco; a Avenida Victor Barreto, entre a Rua Araçá e a Rua Domingos Martins; a Rua 15 de Janeiro, entre a Rua Sady Carnot e a Rua José Muck Filho. ${ }^{34}$

É nesse perímetro que podemos localizar o centro histórico da cidade que passamos a discutir na sequência.

\section{Um centro histórico para Canoas: a reconfiguração do perímetro central urbano}

Uma preocupação das quatro últimas administrações públicas de Canoas é com a revalorização do seu centro urbano, com execução de obras em logradouros como praças, tombamento de prédios históricos, criação de roteiros turísticos, zoneamento, entre outros. Há um esforço de caracterizá-lo, parafraseando Candau ${ }^{35}$ como área de circulação de memórias, com ancoradouros, que remetam a objetos, monumentos, edificações, acontecimentos significativos, com sentidos fortes que promovam compartilhamento de lembranças e deem materialidade à experiência coletiva dos canoenses.

Assim, foram colocados em movimento, memorialistas, pesquisadores de universidades, "guardiões da memória" locais para investigar, debater, analisar e opinar sobre a definição daquilo que deveria ser o tecido histórico urbano a ser preservado. Para tanto, as pesquisadoras, a partir de seus trabalhos, empenharam-se no estudo do estado da arte sobre o conceito de centro histórico e do inventário de patrimônio cultural já realizado na cidade.

Em se tratando do conceito de centro histórico, pode-se acompanhar sua construção a partir do Quadro 1, a seguir.

${ }^{33}$ CANDAU, Joel. Memória e Identidade. São Paulo: Contexto, 2011.

34 CANOAS. Lei $\mathrm{n}^{\circ}$ 456/56. Prefeitura Municipal de Canoas. Disponível em https://leismunicipais.com.br/a1/rs/c/canoas/lei-ordinaria/1956/46/456/lei-ordinaria-n-456-1956-definea-divisao-em-zonas-da-cidade-e-da-outras-providencias?q=pra\%E7a\%20da\%20bandeira. Acesso em 30/04/2016.

${ }^{35}$ CANDAU, Jöel. Bases antropológicas e expressões mundanas da busca patrimonial: memória, tradição e identidade. Revista Memória em Rede. Pelotas, v. 1, n. 1, p. 43-58, dez. 2009/mar. Disponível em: http://www.ufpel.edu.br/ich/memoriaemrede/beta-02-01/index.php/memoriaemrede/article/view/54/53. Acesso em 20/03/2016. 


\section{QUADRO 1: CONSTRUÇÃO DO CONCEITO DE CENTRO HISTÓRICO}

\begin{tabular}{|l|l|}
\hline Documento & Conceito \\
\hline Carta de Atenas (1931) & $\begin{array}{l}\text { Não especifica o que é centro histórico, mas estabelece, pela } \\
\text { primeira vez, critérios para preservação e revitalização de } \\
\text { monumentos e edifícios, considerando-os como testemunhos } \\
\text { de tradições. }\end{array}$ \\
\hline Carta de Veneza (1964) & $\begin{array}{l}\text { Elaborada pelo ICOMOS-Conselho Internacional dos } \\
\text { Monumentos e dos Sítios. Atualizou o conceito de monumento } \\
\text { histórico para além de edificações arquitetônicas, incluindo } \\
\text { sítios urbanos e rurais que tivessem vestígios que remetessem e } \\
\text { simbolizassem etapa marcante do processo histórico. }\end{array}$ \\
\hline $\begin{array}{l}\text { Colóquio sobre conservação } \\
\text { (Quito, 1977) }\end{array}$ & $\begin{array}{l}\text { Definição de centro histórico como espaço físico que foi } \\
\text { condicionado por relações pessoais ao longo do tempo, com } \\
\text { aparência singular e identidade própria. }\end{array}$ \\
\hline $\begin{array}{l}\text { Carta Internacional para a } \\
\text { Salvaguarda das Cidades Históricas } \\
\text { (1987) }\end{array}$ & $\begin{array}{l}\text { Elaborada pelo ICOMOS. Cidades, bairros e centros } \\
\text { importantes são reconhecidos como históricos no caso de } \\
\text { representarem determinadas sociedades ao longo do tempo. }\end{array}$ \\
\hline
\end{tabular}

Fonte: CARTAS Patrimoniais. IPHAN. Brasília. ${ }^{36}$

Ainda sobre o conceito de centro histórico, a Carta de Petrópolis traz indicações a partir do $1^{\circ}$ Seminário Brasileiro para Preservação e Revitalização de Centros Históricos, considerando que toda a cidade é um organismo histórico, mas que existem alguns espaços (um deles pode ser o centro histórico) que condensam testemunhos de um fazer cultural. ${ }^{37}$ Aqui, retomam-se os depoimentos dos memorialistas e dos entrevistados já citados, que insistem na localização do centro histórico de Canoas em determinado espaço, indicando, exatamente, os "fazeres" culturais ali realizados, o que nos leva a Portelli, quando diz que "[...] a memória é um trabalho constante de busca de sentido, que filtra os vestígios da experiência entregando ao esquecimento aquilo que já não tem significado na atualidade [...]". ${ }^{38}$

No caso de Canoas, este espaço corresponde ao núcleo que deu origem à sua urbanização, onde surgiram as primeiras praças, as casas de moradia de pessoas mais abastadas, as pensões, os cinemas, as grandes escolas (Instituto São José em 1908 e Colégio Maria Auxiliadora em 1944) que constituíram o chamado centro cívico em suas versões, a partir da implantação do Município. A seguir, no Quadro 2, apresentase um mapeamento dos elementos que integram o centro histórico da cidade.

\footnotetext{
${ }^{36}$ Disponível em http://portal.iphan.gov.br/pagina/detalhes/226. Acesso em 30/04/2016.

${ }^{37}$ CARTA de Petrópolis. Cartas Patrimoniais. Brasília: IPHAN, 1995.

${ }^{38}$ PORTELLI, Alessandro. História oral como arte da escuta. São Paulo: Letra e Voz, 2016, p. 47.
} 


\section{QUADRO 2: LEVANTAMENTO DE BENS CULTURAIS QUE INTEGRAM O CENTRO HISTÓRICO DE CANOAS (2017)}

\begin{tabular}{|c|c|c|}
\hline Bem cultural & Logradouro & Situação patrimonial \\
\hline Vila Mimosa & Av. Guilherme Shell & Tombado \\
\hline Vila Joana & Av. Guilherme Shell & Tombado \\
\hline Instituto Pestallozi & Av. Guilherme Shell & Inventariado \\
\hline Igreja Matriz São Luiz Gonzaga & Praça da Bandeira & Tombada \\
\hline \multicolumn{3}{|l|}{ Praça da Bandeira } \\
\hline \multicolumn{3}{|l|}{ Largo da Praça de Bandeira } \\
\hline Colégio Maria Auxiliadora & Praça da Bandeira & Inventariado \\
\hline $\begin{array}{l}\text { Prefeitura Municipal de Canoas } \\
\text { Praça da Emancipação } \\
\text { Praça Santos Dumont } \\
\text { (Praça do Avião) }\end{array}$ & $\begin{array}{l}\text { Rua } 15 \text { de Janeiro } \\
\text { Rua } 15 \text { de Janeiro }\end{array}$ & Tombada \\
\hline Taças da Corsan & Rua 15 de Janeiro & Inventariada \\
\hline Conjunto Comercial & Rua 15 de Janeiro & Inventariado \\
\hline Calçadão & $\begin{array}{l}\text { Rua Tiradentes } \\
\text { (Antiga Rua João Pessoa) }\end{array}$ & \\
\hline Antiga Estação do Trem & Rua Victor Barreto & Tombada \\
\hline Edifício Milanez & Rua Victor Barreto & Inventariado \\
\hline Parque dos Rosa & Rua Victor Barreto & Tombada \\
\hline $\begin{array}{l}\text { Universidade La Salle - Capela e Via } \\
\text { Sacra }\end{array}$ & Rua Victor Barreto & Inventariadas \\
\hline Casa Wittrock & Rua Domingos Martins & Tombada \\
\hline \multicolumn{3}{|l|}{ Rodoviária } \\
\hline \multicolumn{3}{|l|}{ Praça da Bíblia } \\
\hline \multicolumn{3}{|l|}{ Colégio Marechal Rondon } \\
\hline Vila Nenê & & Tombada \\
\hline \multicolumn{3}{|l|}{ Av. Inconfidência } \\
\hline Largo da Inconfidência & & \\
\hline
\end{tabular}

Fonte: Elaborado pelas autoras.

Em Canoas, o tecido urbano que conforma os bens culturais listados no Quadro 2 não passou pelo fenômeno da desertificação e nem de abandono, porém, algumas praças que o integram começaram a abrigar moradores de rua e usuários de drogas, o que dificultava o trânsito de pedestres e a sua frequentação. No último ano, já se nota o esvaziamento desses locais por essa população (não se sabe o seu destino $e$ isso é preocupante). Também restaurantes, bares e alternativas de lazer não abrem no 
horário noturno. A partir das 19 horas, paulatinamente, o movimento vai cessando para só recomeçar e se tornar intenso a partir das 9 horas.

De acordo com $\mathrm{Choay}^{39}$, consiste em grande desafio para governantes, a conservação $e$ recuperação do patrimônio cultural, em que pese as edificações $e$ monumentos. Canoas passou a ser objeto de conhecimento histórico e, mesmo não sendo o que se convenciona como cidade histórica, tem elementos que precisam ser protegidos, pois se constituem em vestígios de um estilo de vida de pessoas, famílias vindas dos mais diferentes lugares que lhe dão movimento e vida - a cidade é formada por contingentes de migrantes -, o que lhe confere certas peculiaridades. Trata-se de uma pedagogia da reapropriação, da valorização de bens culturais e de colocá-los a serviço da comunidade. Não se trata apenas de maquiar e embalar a cidade como produto para o consumo cultural, mas tratar o patrimônio sem excluir os menos afortunados e as populações locais.

\section{Considerações finais}

Buscou-se, neste trabalho, problematizar a construção de um "centro histórico", relacionando-o à formação de uma cidade metropolitana brasileira, a partir de diferentes demandas políticas, urbanísticas e patrimoniais. A tarefa requereu algumas considerações bastante específicas, na medida em que o fenômeno da urbanização metropolitana está usualmente desvinculado da noção convencional de "centro histórico", tradicionalmente associado a uma cidade dos tempos coloniais com conjunto harmônico de edificações passíveis de tombamento.

Com efeito, conforme se demonstrou com dados no texto, em termos territoriais e morfológicos, o que se compreende como centro histórico de Canoas é caracterizado por fissuras tais como a BR-116 e a linha ferroviária. A urbanização da cidade foi vertiginosa e transformou um bucólico cenário de veraneio, em menos de trinta anos (1930-1950), naquele que foi considerado o maior reduto operário do Rio Grande do Sul. Em se tratando do patrimônio cultural, esforços têm sido realizados no sentido da preservação de edificações e monumentos associados a outros tempos do desenvolvimento urbano da cidade, senão aquele do planejamento metropolitano.

Quanto às práticas culturais, identificou-se uma profícua brecha para o reconhecimento comunitário da noção de centro histórico. Isso porque se convencionou um perímetro marcado pelas diversas temporalidades que formam a cidade e pela construção de memórias que referenciam edificações representativas para a história local e regional, desde seus usos como ponto de veraneio, passando pelas diversas etnias acolhidas no período pós-guerra $e$, finalmente, pelas demandas da atualidade, que clamam pela extensão do direito à cidade e por um uso pleno do centro, a partir de uma noção integrada de lazer, cultura, comércio e serviços, e meio ambiente.

Espera-se, portanto, pela diversificação de reflexões historiográficas no sentido de pensar as noções de patrimônio cultural e centro histórico, por exemplo, no que tange às regiões metropolitanas brasileiras, sob pena de não considerar cidades cujo desenvolvimento urbano não atende às noções mais tradicionais do ideal de centro

${ }^{39}$ CHOAY, Françoise. A alegoria do patrimônio. São Paulo: Estação Liberdade/Ed. Unesp, 2001. 
histórico. Nas memórias construídas sobre este tipo de espaço em Canoas, perceberam-se discursos em conflito: enquanto alguns remetem a outras possibilidades, outro se firmou e se impôs a partir de uma vontade de memória e em seus suportes. É como se o chamado centro da cidade não quisesse ser esquecido, impondo-se como identidade de uma cidade que ignora os demais espaços de seus antigos começos.

No caso de Canoas, especialmente, ações no âmbito da gestão pública em prol de patrimônios culturais, das indústrias criativas, das festas e sociabilidades são imprescindíveis. Assim, anseia-se que o reconhecimento do centro histórico da cidade, assistido por políticas públicas e associações comunitárias, venha a integrar a reelaboração e reconstrução de significado da memória social urbana de Canoas,

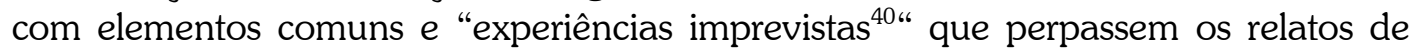
novos narradores, rumo a uma noção $e$ a uma prática citadina mais inclusiva $e$ diversificada.

\section{$\operatorname{son} 2$}

\section{RESUMO}

$\mathrm{O}$ presente artigo apresenta alguns debates historiográficos e desafios no âmbito da gestão pública municipal relacionados à constituição $e$ ao reconhecimento do centro histórico de uma cidade metropolitana do Sul do Brasil, Canoas/RS. Nesses termos, o texto identifica as principais definições que a literatura acadêmica pontua sobre o tema, relacionando-as à formação urbana peculiar de Canoas, marcada pelo vertiginoso processo de metropolização que afetou cidades brasileiras a partir da década de 1950. Utiliza-se como fontes de pesquisa, planos urbanísticos, legislação municipal, além de depoimentos orais, problematizados à luz de contribuições do campo da História Urbana. Compartilham-se conclusões no sentido de como a constituição do centro histórico e de patrimônios culturais a ele associados, entre outras ações, podem contribuir para a reelaboração da ideia cidadedormitório, historicamente associada a Canoas $e$ outras cidades metropolitanas brasileiras, rumo a uma noção e a uma prática citadina mais inclusiva e diversificada.

Palavras Chave: Centro Histórico; Urbanismo; Canoas/RS.

Artigo recebido em 15 nov. 2017.

Aprovado em 16 mai. 2018.

\section{ABSTRACT}

This paper presents some historiographic debates and challenges regarding local public administration and the constitution and acknowledgment of a historic center from a metropolitan city in Southern Brazil (Canoas, state of Rio Grande do Sul). Under these terms, the text identifies the main definitions that academic literature brings about the theme relating to the peculiar urban formation of Canoas city strongly featured by the vertiginous process of metropolization that touched Brazilian cities from the 1950s. We use the historic sources urbanistic sketches, municipal laws, and oral testimonies analyzed under the perspective of Urban History. We share conclusions in order to contribute to the re-elaboration of the "commuter town" idea which is historically associated to Canoas towards to a more inclusive and diversified urban concept and practice.

Keywords: Historic citycenter; Urbanism; Canoas/RS.

${ }^{40}$ PORTELLI, Alessandro. História oral como arte da escuta. São Paulo: Letra e Voz, 2016, p. 15. 